\title{
Zika - another threat on the epidemiological map of the world
}

\author{
Krzysztof Korzeniewski ${ }^{1}$, Dariusz Juszczak ${ }^{2}$, Ewa Zwolińska ${ }^{3}$ \\ ${ }^{1}$ Department of Epidemiology and Tropical Medicine; Military Institute of Medicine, Warsaw, Poland \\ ${ }^{2}$ Commander of the $7^{\text {th }}$ Navy Hospital, Gdansk, Poland \\ ${ }^{3}$ Holy Family Maternity Hospital, Warsaw, Poland
}

\begin{abstract}
Zika fever is an acute infectious disease caused by the Zika virus (ZIKV) of the Flaviviridae family and Flavivirus genus. It is transmitted by day-time active Aedes mosquitoes, and potentially by sexual contacts, blood transfusion, and from mother to foetus (resulting in microcephaly in a child). ZIKV was first isolated from a macaque monkey in the Zika forest in Uganda in 1947. The first case of the Zika fever in a human was recorded in Nigeria in 1954. Until 2007 only 14 cases of the disease were confirmed worldwide. In 2007, there was an outbreak of the Zika fever in Micronesia (Yap Island) with an estimated 5,000 cases. Between 2013 and 2015 a further outbreak of the disease occurred in the Pacific islands: in French Polynesia, New Caledonia, Cook Islands, Easter Island, and Solomon Islands. In 2015, the Zika fever spread to Brazil and more than 20 other countries in the South and Central America. Until March 2016, an estimated 1.6 million autochthonous cases of Zika have been reported globally, with approximately 1.5 million cases recorded in Brazil. Typically, $80 \%$ of Zika infections are asymptomatic. The most common symptoms of the disease include fever, maculopapular rash, muscle and joint pain, conjunctivitis. Zika fever can be diagnosed on the basis of clinical signs (it must be differentiated from dengue, chikungunya), ZIKV identification is also possible by the application of polymerase chain reaction in acutely ill patients and the detection of specific IgM and IgG antibodies to ZIKV. Until today, there is no effective antiviral treatment or an effective vaccine against Zika fever (in case of an infection only symptomatic treatment is applied). In August 2016 in Rio de Janeiro (Brazil) Summer Olympic Games will take place, attracting thousands of athletes and spectators. The fight against the Zika fever and the race against time have gained momentum.
\end{abstract}

(Int Marit Health 2016; 67, 1: 31-37)

Key words: Zika virus, epidemiology, clinical symptoms, prevention

\section{INTRODUCTION}

Zika fever is an acute infectious disease caused by the Zika RNA virus (ZIKV) belonging to family Flaviviridae, genus Flavivirus, which are also the aetiological factors of dengue, yellow fever, Japanese encephalitis, and West Nile fever [1]. ZIKV is transmitted by day-time active female Aedes mosquitoes (mainly Aedes aegypti and Aedes albopictus), vectors of dengue, chikungunya, yellow fever, Japanese encephalitis, and West Nile fever [2]. The true extent of ZIKV vectors is still unknown. The distribution of Aedes mosquitos is now the most extensive ever recorded due to global trade and travel.
It is reported in Sub-Saharan Africa, South and South-East Asia, North Australia, Oceania, South and Central America, southern states of the United States, and also in southern Europe (A. aegypti in Georgia, southern Russia, Madeira; A. albopictus in Italy, France, Spain, Greece, Croatia, Montenegro, Albania, Bulgaria, southern Russia) [3, 4]. ZIKV is not endemic in Poland because Aedes mosquitoes transmitting the virus are not present in the territory of our country; however, there is a potential risk of importing the disease from Zika endemic areas, e.g. South and Central America because of a growing popularity of transcontinental travel among Polish people. 
Potentially, ZIKV is also transmitted by sexual contacts, blood transfusion, and from mother to foetus (causing microcephaly in a child) [5]. Until March 2016, there have been 3 cases of ZIKV infection which might indicate that the virus can be spread through sexual contact. In 2008, an American biologist had been repeatedly bitten by mosquitoes while working in Senegal; a week after his return to the United States he developed symptoms of Zika fever (the infection was confirmed by laboratory tests). Soon a woman with whom the biologist had unprotected sex after returning to the United States (she had not travelled outside the country that year) developed similar symptoms (ZIKV infection was confirmed). In December 2013, in French Polynesia ZIKV was found in the semen of a man, after he had fallen ill with Zika fever. In February 2016, in Texas (United States) a man contracted Zika fever after sexual contact with a woman who had recently returned from endemic region in South America [6-8]. Until now, there are no confirmed cases of ZIKV transmission through blood transfusion. A potential risk is suspected based on positive tests for ZIKV in 42 blood donors studied during the Zika outbreak in French Polynesia at the turn of the year 2013/2014. At the time of blood transfusion they were asymptomatic; 11 of the infected donors reported symptoms of Zika fever after their donation [9]. In 2015, in Brazil ZIKV was detected in the amniotic fluid of 2 pregnant women whose foetuses had microcephaly [10]. There have been further cases of the disease from this country (confirmed by polymerase chain reaction [PCR] tests of tissues of miscarriages and brain tissues from newborns with microcephaly, who had died shortly after birth) [11]. The number of microcephaly cases among newborn children in Brazil, the country with the highest number of ZIKV infections in the world, has increased from 150 cases per year in the period 2010-2014 to 1,248 in 2015 (as of 28 November 2015). The highest prevalence of microcephaly among newborns was recorded in the state of Pernambuco (646; the reported rate 77 times higher than in the previous 5 years) [12]. On 2 January 2016, the Ministry of Health of Brazil announced that the number of suspected cases of microcephaly across the country had reached 3,174 cases, including 38 deaths. The worst affected regions are northeastern states of Pernambuco, Paraiba and Bahia, where about $1 \%$ of newborns are suspected of being microcephalic [13]. According to World Health Organisation (WHO), a link between ZIKV and microcephaly is strongly suspected but still not scientifically proven [14].

\section{EPIDEMIOLOGY}

Zika virus was first isolated from a macaque monkey in the Zika forest in Uganda in 1947 [15]. In 1948, ZIKV was isolated from Aedes mosquito (A. africanus), which was considered to be a vector for Zika transmission [16]. Over the next decades the ZIKV was isolated from other mosquitos of the Aedes genus: A. aegypti, A. apicoargenteus, A. luteocephalus, A. vitattus, A. furcifer, A. albopictus [17]. The first symptomatic case of the Zika fever in a human was recorded in Nigeria in 1954 [18]. Until 2007 only 14 cases of the disease were confirmed worldwide [17]. The first outbreak of the Zika fever occurred in Micronesia (Yap Island) in 2007. During the outbreak Duffy et al. [17] collected blood samples from 557 residents of Yap Island; 414 (74\%) of the tested individuals had IgM antibody against ZIKV and 156 $(38 \%)$ of the infected, with a mean age of 36 (61\% women; usually the elderly), reported symptoms of the illness during the outbreak period. Researchers estimated that 5,005 of the 6,892 Yap residents, who were 3 years of age or older, became infected with ZIKV in 2007 [17]. These were the first cases of the disease recorded outside Africa or Asia [19]. Between 2013 and 2015 further outbreaks occurred in some Pacific islands: in French Polynesia, New Caledonia, Cook Islands, Easter Island, and Solomon Islands [12]. In December 2013 ZIKV was suspected to be responsible for an estimated 19,000 cases of dengue-like syndrome in French Polynesia [20]. In 2015, Zika fever spread to Brazil and more than 20 other countries in South and Central America. Until February 2016, an estimated 1.6 million autochthonous cases of Zika have been reported globally, mainly in South and Central America (including approximately 1.5 million cases in Brazil alone, over 30,000 cases in Columbia, more than 4,600 cases in Venezuela) (Table 1), less commonly in Africa (over 7,000 in Cape Verde) and on the islands of Oceania (Tonga, American Samoa, Samoa) [21]. As of 17 February 2016, the Centres for Disease Control and Prevention (CDC) reported 82-travel associated Zika fever cases in the United States, with no locally acquired vector-borne infections [22]. Single cases of imported Zika infections have also been recorded in Europe [23, 24], China [25], and Australia [26]. A continuing expansion of the infection vector to all parts of the world may result in the occurrence of new ZIKV outbreaks, especially in densely populated urban areas [27]. On 1 February 2016, the WHO declared the ZIKV outbreak to be a Public Health Emergency of International Concern. The WHO declaration may potentially reduce the number of visitors to the Rio Olympic Games in 2016 [28].

\section{CLINICAL MANIFESTATIONS}

Eighty per cent of Zika infections are asymptomatic [29]. Clinical manifestations of Zika fever are similar to other arboviral infections, especially to dengue and chikungunya, therefore Zika fever should be first differentiated from these two conditions (Table 2). Other illnesses presenting with fever and skin rash, which should be differentiated from the Zika fever are measles, rubella, O'nyong-nyong, leptospirosis, rickettsioses. 
Table 1. Cumulative Zika suspected and confirmed autochthonous cases in the Americas, 2015-2016. Source: WHO IHR Regional Contact Point for the Americas; the Ministry of Health websites, 25 February 2016

\begin{tabular}{|c|c|c|c|}
\hline Country/territory & $\begin{array}{l}\text { Suspected } \\
\text { cases }\end{array}$ & $\begin{array}{l}\text { Confirmed } \\
\text { cases }\end{array}$ & $\begin{array}{l}\text { Deaths from } \\
\text { Zika cases }\end{array}$ \\
\hline \multicolumn{4}{|l|}{ South America } \\
\hline Brazil $^{1}$ & 72,062 & 534 & 4 \\
\hline Colombia & 35,399 & 1,612 & 3 \\
\hline Venezuela & 4,696 & 4 & 1 \\
\hline Suriname & 1,097 & 6 & 4 \\
\hline French Guyana & 790 & 99 & 0 \\
\hline Ecuador & 0 & 25 & 0 \\
\hline Paraguay & 0 & 6 & 0 \\
\hline Bolivia & 0 & 1 & 0 \\
\hline Guyana & 0 & 1 & 0 \\
\hline \multicolumn{4}{|l|}{ Central America } \\
\hline El Salvador & 8,584 & 3 & 0 \\
\hline Honduras & 4,590 & 2 & 0 \\
\hline Guatemala & 278 & 105 & 0 \\
\hline Mexico & 0 & 93 & 0 \\
\hline Panama & 0 & 86 & 0 \\
\hline Nicaragua & 0 & 66 & 0 \\
\hline Costa Rica & 0 & 3 & 0 \\
\hline \multicolumn{4}{|l|}{ Caribbean } \\
\hline Martinique & 6,050 & 12 & 0 \\
\hline Haiti & 329 & 5 & 0 \\
\hline Dominican Republic & 305 & 18 & 0 \\
\hline Guadeloupe & 221 & 25 & 0 \\
\hline $\begin{array}{l}\text { United States } \\
\text { Virgin Island }\end{array}$ & 59 & 4 & 0 \\
\hline Puerto Rico & 0 & 30 & 0 \\
\hline Saint Martin & 0 & 7 & 0 \\
\hline Barbados & 0 & 7 & 0 \\
\hline Aruba & 0 & 4 & 0 \\
\hline Others & 0 & 7 & 0 \\
\hline Total & 134,460 & 2,765 & 12 \\
\hline
\end{tabular}

${ }^{1}$ The suspected cases in Brazil are unofficial. Brazilian Ministry of Health reported minimum 497,523 and 1,482,701 as maximum estimated cases.

The incubation period of the Zika fever after a bite by ZIKV-infected mosquito ranges from 3 to 12 days and is similar to other infections caused by flaviviruses [2]. Clinical signs typically persist for 2-7 days [12]. The most common clinical manifestations include low-grade fever, transient joint pain (mainly smaller joints of hands and feet), maculopapular rash (covering the face, the neck, the trunk, the extremities: first the upper and next the lower), non-purulent conjunctivitis, muscle pain, mild cephalea, vertigo, retroorbital pain, malaise. The illness usually has a mild and self-limiting course [30, 31].

There is a link between Zika infection and neurologic conditions in newborn children (microcephaly) and adults (Guillain-Barré syndrome [GBS]) [32]. In the French Polynesian outbreak, 73 cases of GBS (a rapid onset of muscle weakness which can progress to paralysis) occurred in a population of 270,000; GBS may have been associated with the ZIKV $[12,33]$. Some countries affected by Zika outbreaks have recorded an increase in GBS cases, including 3 deaths due to Zika related GBS reported in Colombia [34].

In December 2015, the European CDC issued a comprehensive update on the possible association of ZIKV with congenital microcephaly. Data suggest that newborns of mothers who became infected with the ZIKV during the first trimester of pregnancy are at an increased risk for microcephaly [12].

Microcephaly is a pathological condition defined as a reduction in head circumference of two standard deviations $(\leq 2 \mathrm{SD})$ below the mean for age, sex and race. Before the Zika outbreak microcephaly occurred in $0.07 \%$ of newborns in Brazil, it now occurs in 1-2\% [35]. Apart from microcephaly, other prenatally diagnosed foetal defects of the central nervous system were observed in pregnant women infected with ZIKV, including intracranial calcification, ventriculomegaly and cerebral hypoplasia [36]. In Pernambuco state in Brazil, among 55 suspected microcephalic babies of which 40 cases were related to ZIKV, about $40 \%$ also exhibited ocular malformations (retinal atrophy, pigment alteration) [37].

Interim Zika fever case definition (according to Pan American Health Organisation) [38]:

- Suspected case: patient with rash or elevated body temperature $\left(>37.2^{\circ} \mathrm{C}\right)$ with at least one of the following symptoms (not explained by other medical conditions): arthralgia or myalgia, non-purulent conjunctivitis or conjunctival hyperaemia, headache or malaise.

- Confirmed case: a suspected case of Zika fever with laboratory positive result for ZIKV.

\section{DIAGNOSTICS}

Zika diagnosis can be based on anamnesis (travel to endemic areas), clinical signs (however, it is difficult to diagnose Zika fever based on clinical signs alone due to overlaps with other arboviral infections that are endemic to similar areas, e.g. dengue, chikungunya) [32], RNA ZIKV identification by PCR on serum in acutely ill patients $(<7$ days after symptoms onset) and detection of specific IgM and IgG antibodies to ZIKV with ELISA test ( $\geq 4$ days after symptoms onset) (Fig. 1). The serological diagnosis of ZIKV 
Table 2. Comparison of clinical signs of Zika fever, dengue, and chikungunya. Source: Prof. Carlos Brito, Federal University of Pernambuco, Brazil, December 2015

\begin{tabular}{|c|c|c|c|}
\hline Clinical signs & Zika fever & Dengue & Chikungunya \\
\hline Fever (duration) & $\begin{array}{l}\text { No fever or subfebrile tempera- } \\
\text { ture } \leq 38^{\circ} \mathrm{C}(1-2 \text { days })\end{array}$ & $\begin{array}{l}\text { Over } 38^{\circ} \mathrm{C} \\
(4-7 \text { days })\end{array}$ & $\begin{array}{l}\text { Over } 38^{\circ} \mathrm{C} \\
\text { (2-3 days) }\end{array}$ \\
\hline Skin rash & $\begin{array}{l}\text { On } 1^{\text {st }} \text { on } 2^{\text {nd }} \text { day after the } \\
\text { onset }-90 \% \text { cases }\end{array}$ & $\begin{array}{l}\text { On } 4^{\text {th }} \text { day after the onset } \\
-30-50 \% \text { cases }\end{array}$ & $\begin{array}{l}\text { On } 2^{\text {nd }}-5^{\text {th }} \text { after the onset } \\
-50 \% \text { cases }\end{array}$ \\
\hline Myalgia (frequency) & $++/+++$ & $+++/+++$ & $+/+++$ \\
\hline Arthralgia (frequency) & $++/+++$ & $+/+++$ & $+++/+++$ \\
\hline Arthralgia (intensity) & Mild/moderate & Mild & Moderate/severe \\
\hline Joint swelling & Common, mild & Rare & Common, moderate/severe \\
\hline Non-purulent conjunctivitis & $50-90 \%$ cases & rarely & $30 \%$ cases \\
\hline Lymphadenopathy & + & ++ & ++ \\
\hline Hepatomegaly & - & +++ & - \\
\hline Leucopoenia/thrombopoenia & - & +++ & +++ \\
\hline Cephalea (frequency and intensity) & ++ & +++ & ++ \\
\hline Pruritus & Moderate/severe & Mild & Mild \\
\hline Neurological symptoms & $\begin{array}{l}\text { More common than in dengue } \\
\text { and chikungunya }\end{array}$ & Rare & $\begin{array}{l}\text { Rare (most common } \\
\text { in newborns) }\end{array}$ \\
\hline
\end{tabular}

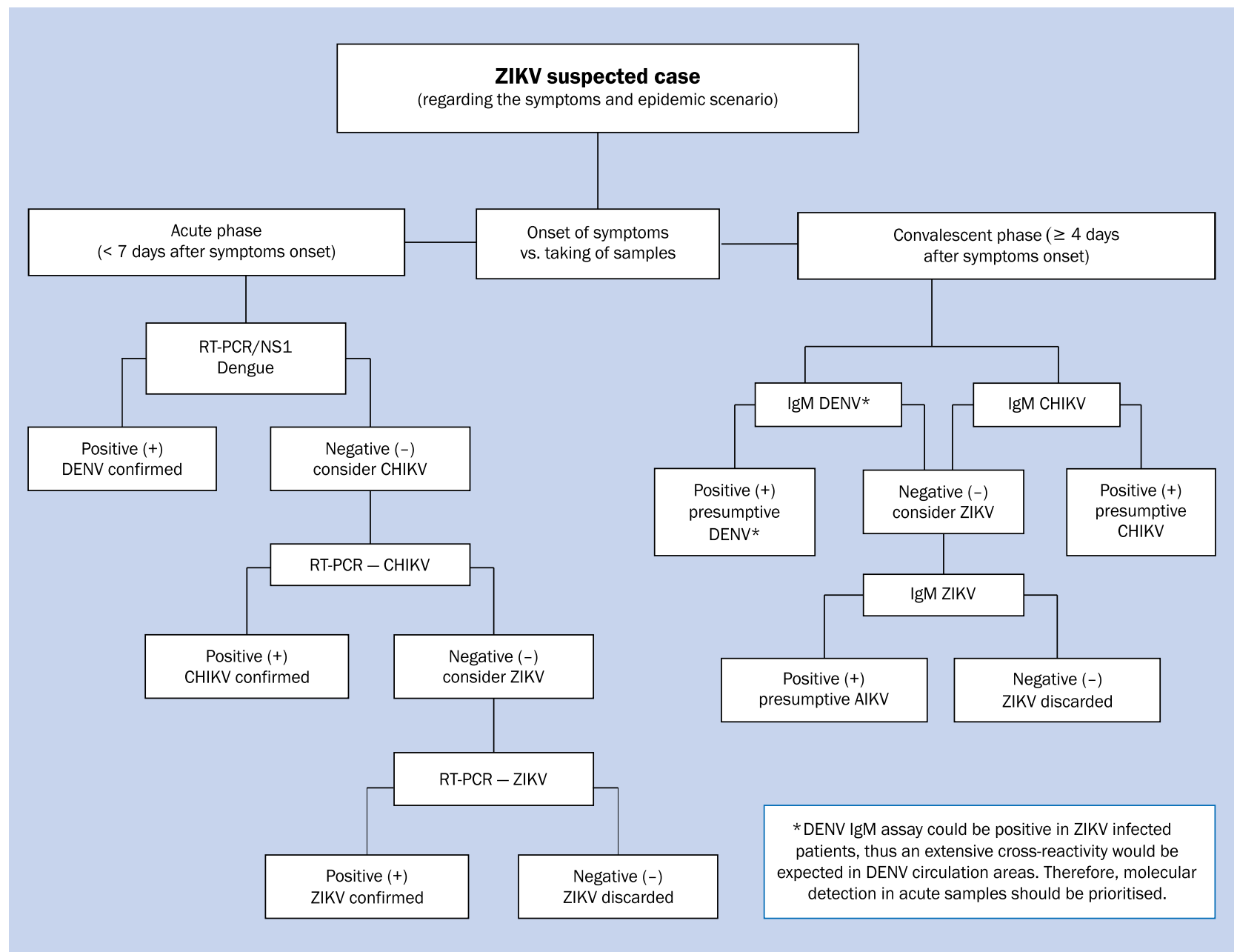

Figure 1. Algorithm for detection of Zika virus (ZIKV) suspected cases. Source: Pan American Health Organisation. World Health Organisation Regional Office for the Americas, 29 June 2015, Centres for Disease Control and Prevention. Division of Vector-Borne Diseases, 07 February 2016; CHIKV - chikungunya virus; DENV - dengue virus; RT-PCR - real time polymerase chain reaction 


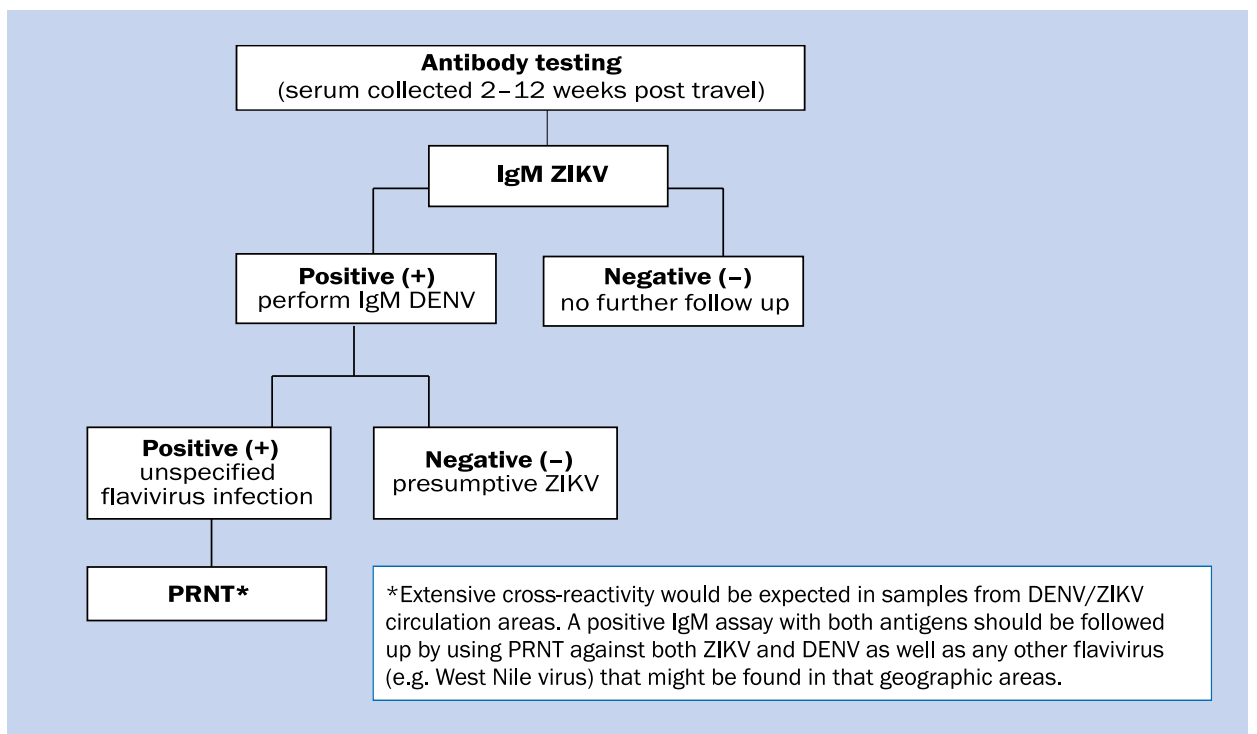

Figure 2. Algorithm for detection of Zika virus (ZIKV) suspected cases in asymptomatic, pregnant women. Source: Centres for Disease Control and Prevention. Division of Vector-Borne Diseases, 07 February 2016; PRNT - plaque-reduction neutralisation tests; rest abbreviations as in Figure 1

may be impeded by cross-reactivity of ZIKV antibodies with other viruses. The methods currently available to test for Zika antibodies cross-react especially with dengue antibodies. An IgM-positive result in a dengue or Zika ELISA test can only be considered indicative of a recent flavivirus infection. Plaque-reduction neutralisation tests (PRNT) can be performed and may be specific [39]. Some authors have reported using PCR of the urine to diagnose ZIKV, but this has not been independently confirmed [40].

Pregnant women who have travelled to areas with ZIKV transmission should be tested for suspected ZIKV infection [39] (Fig. 2) and foetal ultrasound scan should be performed. Babies born to ZIKV-positive mothers also should be screened for ZIKV infection. CDC recommends testing of infants with both molecular and serologic assays (RT-PCR, IgM ELISA, PRNT), as well as physical investigation for neurologic abnormalities, splenomegaly, hepatomegaly, skin lesions, hearing evaluation, eye examination. Testing should be done for any abnormalities encountered in other congenital viral infections such as toxoplasmosis, rubella, cytomegalovirus, and herpes simplex virus infection (TORCH syndrome) [29]. In order to differentiate Zika fever from other arboviral infections attention should be paid to laboratory tests results, especially the levels of leukocytes and platelets, which are within normal range in case of a Zika infection, but tend to be reduced in case of dengue or chikungunya.

\section{TREATMENT AND PREVENTION}

Only symptomatic treatment is applied to manage the Zika infection (antipyretics, analgesics, antipruritics and medications maintaining nutrition and hydration). As yet, there are no antiviral medications available for ZIKV [41]. Nonsteroidal anti-inflammatory drugs should be used only when dengue has been ruled out to reduce the risk of bleeding. Paracetamol is the drug of choice in pregnancy (aspirin is contraindicated). In case of central nervous system complications (microcephaly, GBS) neurological medications are introduced [32]. Although very rare, intensive care admission may be warranted for patients with signs of sepsis or multi-organ failure with the rise in fever, tachycardia, hypotension, renal dysfunction, liver dysfunction, respiratory distress, coagulopathy [33].

To prevent the transmission of ZIKV, WHO recommends mosquito avoidance by using insect repellents (containing DEET, picaridin, or IR3535, considered safe in pregnant and breastfeeding women), wearing long-sleeved shirts and long trousers to cover the body, and using screens and mosquito nets to exclude flying insects from dwellings or sleeping areas [42, 43]. CDC also recommends that water containers found around households (potential breeding sites for mosquitoes) should be cleaned once a week and that larvae should be killed with recommended larvicides. CDC advises pregnant women against travelling to Zika endemic areas in the Caribbean, Central and South America [44]. Because of the suspicion that ZIKV may be sexually transmitted, travellers are recommended to avoid sexual contacts in Zika endemic regions or use condoms throughout the stay as well as 2 weeks after returning from countries with Zika transmission. Women who plan to get pregnant and their male partners should follow all the necessary safety precautions in order to avoid mosquito bites [44]. Officials in Brazil, 
Colombia, Ecuador, El Salvador and Jamaica have urged their female citizens to postpone pregnancies [45]. Men who have travelled to ZIKV affected areas who have a pregnant partner are advised to abstain from sexual activity or consistently use condoms during sex for the duration of the pregnancy [12]. To date, there have been no confirmed reports of ZIKV transmission through breastfeeding, although it had been found in human milk. Breastfeeding does not need to be discontinued in Zika endemic areas; howev$\mathrm{er}$, this route of transmission should not be ignored [29]. Because it is suspected that ZIKV may be potentially transmitted via blood transfusion, precautions need to be taken to avoid the pathogen entering public blood banks (ZIKV screening) [5].

Effective vaccines exist for several flaviviruses (yellow fever, Japanese encephalitis, tick-borne encephalitis); however, there is no effective vaccine against ZIKV infection as yet [43], just as there are still no vaccines available against dengue, chikungunya and West Nile fever, the most widespread arthropod-borne viral diseases in the Western Hemisphere over the past 20 years [32]. Returned travellers who have developed symptoms indicative of the Zika infection or other vector-borne disease manifesting with fever and skin rash within 3 weeks after coming back from a ZIKV endemic region are advised to contact their health care provider [12].

In August 2016 in Rio de Janeiro (Brazil) Summer Olympic Games are going to take place, attracting thousands of athletes and spectators from all over the world. At the end of January 2016, Rio's municipal administration announced plans to try to prevent the spread of the Zika infections during the Olympic Games in the city. The fight against the Zika fever and the race against time have gained momentum.

\section{REFERENCES}

1. Kuno G, Chang GJ, Tsuchiya KR, Karabatsos N, Cropp CB. Phylogeny of the genus Flavivirus. J Virol 1998; 72: 73-83.

2. Sikka V, Chattu VK, Popli RK et al. The emergence of zika virus as a global health security threat: A review and a consensus statement of the INDUSEM Joint workin Group (JWG). J Glob Infect Dis 2016; 8: 3-15.

3. Kraemer MU, Sinka ME, Duda KA, Mylne AQ, Shearer FM, Barker, Brady OJ. The global compendium Aedes aegypti and A. albopictus occurrence. Sci Data 2015; 2: 150035.

4. European Centre for Disease Prevention and Control. Mosquito maps. Available at: http://ecdc.europa.eu/en/healthtopics/vectors/ vector-maps/Pages/VBORNET_maps.aspx. Accessed: 21 Feb 2016.

5. Gatherer D, Kohl A. Zika virus: a previously slow pandemic spreads rapidly through the Americas. J Gen Virol 2016; 97: 269-273.

6. Oster AM, Brooks JT, Stryker JE, Kachur RE, Mead P, Pesik NT, Petersen LR. Interim Guidelines for Prevention of Sexual Transmission of Zika Virus - United States, 2016. MMWR Morb Mortal Wkly Rep 2016; 65: 120-121.

7. Foy BD, Kobylinski KC, Chilson Foy JL et al. Probable non-vector -borne transmission of Zika virus, Colorado, USA. Emerg Infect Dis 2011; $17: 880-882$.
8. Musso D, Roche C, Robin E, Nhan T, Teissier A, Cao-Lormeau VM. Potential sexual transmission of Zika virus. Emerg Infect Dis 2015; 21: 359-361.

9. Musso D, Nhan T, Robin E et al. Potential for Zika virus transmission through blood transfusion demonstrated during an outbreak in French Polynesia, November 2013 to February 2014. Euro Surveill 2014; 19: pii: 20761.

10. Schuler-Faccini L, Ribeiro EMet al. Brazilian Medical Genetics Society - Zika Embryopathy Task Force. Possible Association Between Zika Virus Infection and Microcephaly - Brazil, 2015. MMWR Morb Mortal Wkly Rep 2016; 65: 59-62.

11. Martines RB, Bhatnagar J, Keating MK et al. Notes from the Field: Evidence of Zika Virus Infection in Brain and Placental Tissues from Two Congenitally Infected Newborns and Two Fetal Losses - Brazil, 2015. MMWR Morb Mortal Wkly Rep 2016; 65: 159-160.

12. European Centre for Disease Prevention and Control. Rapid risk assessment. Zika virus epidemic in the Americas: potential association with microcephaly and Guillain-Barré syndrome. Available at: zika-virus-americas-associacion-with-microcephaly-rapid-risk-assessment. pdf. 10 Dec 2015. Accessed: 20 Feb 2016.

13. World Health Organization. Microcephaly - Brazil. Available at: http://www.who.int/csr/ don/8-january-2016-brazil-microcephaly/ en/. 8 Jan 2016. Accessed: 20 Feb 2016.

14. Pan American Health Organization. WHO Zika situation report: February 5th 2016. Neurological syndrome and congenital anomalies. Available at: http://www.paho.org/ HQ/index.php?option=com_content\&view=article\&id=11657: who-latest-zika-situation-report\&ltemid=41716\&lang=fr. Accessed: $21 \mathrm{Feb} 2016$.

15. Dick GW, Kitchen SF, Haddow AJ. Zika virus isolations and serological specificity. Trans R Soc Trop Med Hyg 1952; 46: 509-520.

16. Dick GW. Zika virus pathogenicity and physical properties. Trans $R$ Soc Trop Med Hyg 1952; 46: 521-534.

17. Duffy MR, Chen TH, Hancock WT et al. Zika virus outbreak on Yap Island, Federated States of Micronesia. N Engl J Med 2009; 360: 2536-2543.

18. Macnamara FN. Zika virus: a report on three cases of human infection during an epidemic of jaundice in Nigeria. Trans R Soc Trop Med Hyg 1954; 48: 139-145.

19. Hayes BE. Zika Virus Outside Africa. Emerg Infect Dis 2009; 15: 1347-1350.

20. Cao-Lormeau VM, Roche C, Teissier A et al. Zika virus, French polynesia, South pacific, 2013. Emerg Infect Dis. 2014; 20: 1085-1086.

21. Garcia E, Yactayo S, Nishino K, Millot V, Perea W, Briand S. Zika virus infection: global update on epidemiology and potentially associated clinical manifestations. Wkly Epidemiol Rec 2016; 91: 73-81.

22. Centers for Disease Control and Prevention. Zika virus disease in the United States, 2015-2016. Available at: http://www.cdc.gov/ zika/geo/united-states.html. Accessed: 21 Feb 2016.

23. Zammarchi L, Tappe D, Fortuna $C$ et al. Zika virus infection in a traveller returning to Europe from Brazil, March 2015. Euro Surveill 2015; 20: pii: 21153.

24. Venturi G, Zammarchi L, Fortuna $C$ et al. An autochthonous case of Zika due to possible sexual transmission, Florence, Italy, 2014. Euro Surveill 2016; 21: pii: 30148.

25. Rajagopalan M, Clare J. China confirms first case of Ziku virus Xinhua. Reuters 10 Feb 2016. Available at: http://in.reuters.com/ article/health-zika-china-idINKCNOVI1VG. Accessed: 21 Feb 2016.

26. Barker A. Zika virus found in Australian travellers returning from South America, virologist says. ABC News 26 Jan 2016. Available at: http://www.abc.net.au/news/2016-01-26/zika-virus-detected -in-australians-returning-from-south-america/7115568. Accessed: 21 Feb 2016. 
27. loos S, Mallet HP, Leparc Goffart I, Gauthier V, Cardoso T, Herida M. Current Zika virus epidemiology and recent epidemics. Med Mal Infect 2014; 44: 302-307.

28. ProMED-mail. Zika virus: WHO declares Public Health Emergency of International Concern (PHEIC). 01 Feb 2016. International Society for Infectious Diseases. Available at: http://www.promedmail.org. Accessed: 28 Feb 2016.

29. Staples JE, Dziuban EJ, Fischer M, Cragan JD, Rasmussen SA, Cannon MJ, et al. Interim Guidelines for the Evaluation and Testing of Infants with Possible Congenital Zika Virus Infection - United States, 2016. MMWR Morb Mortal Wkly Rep 2016;65(3): 63-67.

30. Lanciotti RS, Kosoy OL, Laven JJ et al. Genetic and serologic properties of Zika virus associated with an epidemic, Yap State, Micronesia, 2007. Emeg Infect Dis 2008; 14: 1232-1239.

31. Musso D, Nilles EJ, Cao-Lormeau VM. Rapid spread of emerging Zika virus in the Pacific area. Clin Microbiol Infect 2014; 20: 595-596.

32. Fauci AS, Morens DM. Zika Virus in the Americas - Yet Another Arbovirus Threat. N Engl J Med 2016; 374: 601-604.

33. Oehler E, Watrin L, Larre P et al. Zika virus infection complicated by Guillain-Barre syndrome: case report, French Polynesia, December 2013. Euro Surveill 2014; 19: 20720.

34. USA Today. Colombia: 3 dead from Zika-linked Guillain-Barre syndrome. 05 Feb 2016. Available at: http://www.usatoday.com/story/ news/2016/02/05/colombia-3-deaths-zika-linked-guillain-barresyndrome/79882600/. Accessed: 28 Feb 2016.

35. Dyer O. Sixty seconds on... Zika virus. BMJ 2016; 352: i467.

36. Oliveira Melo AS, Malinger G, Ximenes R, Szejnfeld PO, Alves Sampaio S, Bispo de Filippis AM. Zika virus intrauterine infection causes fetal brain abnormality and microcephaly: tip of the iceberg? Ultrasound Obstet Gynecol 2016; 47: 6-7.
37. ProMED-mail. Zika virus: Americas, Asia. 28 Jan 2016. International Society for Infectious Diseases. Available at: http://www.promedmail.org. Accessed: 28 Feb 2016.

38. Pan American Health Organization. World Health Organization Regional Office for the Americas. Guidance for reporting ZIKV. Available at: http://www.paho.org/hq/index. php?option=com_content\&view=article\&id=11117\&ltemid=41532\&lang=en. Accessed: 25 Feb 2016 .

39. Centers for Disease Control and Prevention. Division of Vector-Borne Diseases. Revised diagnostic testing for Zika, chikungunya, and dengue viruses in US Public Health Laboratories. 7 Feb 2016. Available at: http://www.cdc.gov/zika/pdfs/denvchikvzikv-testing-algorithm. pdf. Accessed: 28 Feb 2016.

40. Shinohara K, Kutsuna S, Takasaki T et al. Zika fever imported from Thailand to Japan, and diagnosed by PCR in the urines. J Travel Med. 2016; 23: pii: tav011.

41. Tappe D, Rissland J, Gabriel M et al. First case of laboratory-confirmed Zika virus infection imported into Europe, November 2013. Euro Surveill 2014; 19: pii: 20685.

42. World Health Organization. Zika virus fact sheet. February 2016. Available at: http://www.who.int/emergencies/zika-virus/timeline/ en/. Accessed: 28 Feb 2016.

43. Chen LH, Hamer DH. Zika virus: rapid spread in the Western Hemisphere. Ann Intern Med 2016 Feb 2. www.annals.org.

44. Centers for Disease Control and Prevention. Surveillance and Control of Aedes aegypti and Aedes albopictus in the United States. U.S. Department of Health \& Human Services. Available at: http://www. cdc.gov/chikungunya/resources/vector-control.html. Accessed: 25 Feb 2016.

45. Dyer 0. Jamaica advises women to avoid pregnancy as Zika virus approaches. BMJ 2016; 352: i383. 